University of Nebraska - Lincoln

DigitalCommons@University of Nebraska - Lincoln

USDA National Wildlife Research Center - Staff

Publications

U.S. Department of Agriculture: Animal and Plant Health Inspection Service

July 2006

\title{
Using a general indexing paradigm to monitor rodent populations
}

Richard M. Engeman

USDA-APHIS-Wildlife Services, s_r100@yahoo.com

Desley Whisson

University of California, Davis, $C A$

Follow this and additional works at: https://digitalcommons.unl.edu/icwdm_usdanwrc

Part of the Environmental Sciences Commons

Engeman, Richard M. and Whisson, Desley, "Using a general indexing paradigm to monitor rodent populations" (2006). USDA National Wildlife Research Center - Staff Publications. 416.

https://digitalcommons.unl.edu/icwdm_usdanwrc/416

This Article is brought to you for free and open access by the U.S. Department of Agriculture: Animal and Plant Health Inspection Service at DigitalCommons@University of Nebraska - Lincoln. It has been accepted for inclusion in USDA National Wildlife Research Center - Staff Publications by an authorized administrator of DigitalCommons@University of Nebraska - Lincoln. 


\title{
Using a general indexing paradigm to monitor rodent populations
}

\author{
Richard Engeman $^{\mathrm{a}, *}$, Desley Whisson ${ }^{\mathrm{b}, 1}$ \\ ${ }^{a}$ National Wildlife Research Center, 4101 Laporte Avenue, Fort Collins, CO 80521-2154, USA \\ ${ }^{\mathrm{b}}$ Department of Wildlife, Fish and Conservation Biology, University of California, One Shields Ave, Davis, CA 95616, USA
}

Received 20 June 2005; received in revised form 21 March 2006; accepted 23 March 2006

\begin{abstract}
Population monitoring is a valuable component to managing invasive rodent populations. Indices can be efficient methods for monitoring rodent populations, as more labor-intensive density estimation procedures often are impractical or invalid to apply. Many monitoring objectives can be couched in an indexing framework. Indexing procedures obtain maximal utility if they exhibit key characteristics, including being practical to apply, being sensitive to population changes or differences in the target species, having an inherent variance formula to estimate precision of index values, and relying on as few assumptions as possible. Here, a general indexing paradigm that promotes the characteristics that make indices most useful is specifically applied to rodent monitoring scenarios. Observations are made at stations located throughout the area of interest. Stations can take many forms, depending on the observations, and range from points for visual counts to tracking plots (or tiles), bait blocks, chew cards, camera stations, trap lines and many others. Thus, a wide variety of observation methods for many animal species can fit into this format. Observations are made at each station on multiple occasions for each indexing session. Collection of geographic location data for each station is encouraged. No assumptions of independence are made among stations or observation occasions, and measurements made at each station are required to be continuous or unboundedly discrete. The formula for a general index is presented along with a derived variance formula. Issues relevant to the application of this methodology to rodent populations, and indices in general, are discussed.
\end{abstract}

Published by Elsevier Ltd.

Keywords: Abundance; Density estimate; Population monitoring; Relative abundance

\section{Introduction}

Rodents can conflict greatly with human enterprises by damaging constructions and agriculture, spreading diseases, and negatively impacting species of concern. Monitoring rodent populations is crucial to their efficient management. Ideally, the exact number of animals within an area of interest would be known, but in reality, this is a rare circumstance and population size is usually assessed through sampling procedures. Density estimation procedures such as mark-capture methods (e.g. Otis et al., 1978)

\footnotetext{
*Corresponding author. Tel.: + 19702666091 ; fax: + 19702666089 .

E-mail address: richard.m.engeman@aphis.usda.gov (R. Engeman).

${ }^{1}$ Now at DEH, Regional Conservation Programs Unit, P.O. Box 39, Kingscote, SA 5223, Australia.
}

and line transect (e.g. Burnham et al., 1980) attempt to estimate the actual number or density of animals in an area, but they are often difficult or expensive to implement, and they may require difficult-to-meet analytical assumptions that when violated result in estimates of questionable quality (see Krebs, 1998 and Leidloff, 2000) for an examination of potential problems with mark-recapture methods and Burnham et al. (1980) for a similar discussion on line transect methods). Indexing procedures are additional tools in the armamentarium of methods available for monitoring wildlife populations (e.g. Engeman, 2003), and problems couched in terms of absolute density often can be redefined such that an index parameter reflective of abundance provides an efficient solution (Caughley, 1977; Krebs, 1998). Examples include tracking rates, feces deposition, capture rates, bait consumption, or visual 
observations, among a host of possibilities. Indices are not estimates of actual population numbers, so they are applied to make relative comparisons between populations or to monitor trends within a population (e.g. Caughley, 1977; Krebs, 1998). Here, a general observational and analytical paradigm (Engeman, 2005) is described into which a wide variety of measurement methods for indexing many rodent species can fit.

\section{Desirable qualities for an index}

An indexing method obtains maximal utility when it possesses certain desirable characteristics, some resulting from the data structure or the analytical method, and others from observational methods.

\subsection{Practicality}

An index method must be practical to apply. This might be said of any sampling procedure, but practicality is a prime deciding factor for choosing to use an index. The index method should be user-friendly, with the procedures and concepts for recording information easily understood. Methods must impose minimal inconvenience for landowners and managers.

\subsection{Sensitivity}

An index should be sensitive to differences in population size, whether comparing multiple populations simultaneously, or monitoring changes within the same population. The measurements upon which the index is based should change if the population changes. For example, structure counts often are used as indices to compare muskrat (Ondatra zibethicus) populations between areas (Proulx and Gilbert, 1984). However, the longevity of structures built by muskrats make structure counts an inefficient method to index short-term changes such as control efforts. Rigorously designed visual counts may provide suitable sensitivity for this application (Engeman and Whisson, 2003).

\subsection{Precision and variance estimation}

Given an appropriate observation, the ability of an index to statistically detect population differences increases with its precision (Engeman, 2005). When the relevant question concerns whether a population has declined or increased, precision determines the quality of comparisons for elucidating trends, making estimates of animal numbers unnecessary (e.g. Caughley and Sinclair, 1994). An easily applied index encourages more observations, with consequent improvements in precision.

Since precision is essential to an index, it follows that the data structure, measurements, and index calculations define an inherent estimate of variance, which in turn allows for the application of standard statistical procedures. Oftentimes, observations are made and an index produced, but no estimate of precision is available, or the only avenue for estimating variance is to subdivide the data into units that can contribute to the variance calculations. This approach, especially if done post hoc, can produce variance estimates subjectively related to definition of the units.

\subsection{Robustness}

The most robust inferences are produced if the calculated index and associated variance are burdened with as few assumptions as possible about the data structure and the distribution of the observations. Violation of analytical assumptions is the bane of density estimation methods (see Krebs, 1998 for a general overview), and can be a compelling reason to apply an index rather than estimating density. An index heavily reliant on analytical assumptions is of minimal utility.

\subsection{Tested prior to application}

Prior to applying an indexing method on an operational basis, it should have been tested on that species. For example, the open-hole method (Engeman et al., 1993, 1999) has been highly successful for monitoring northern pocket gophers (Thomomys talpoides), but when applied to the nearly identical Townsend pocket gopher (Thomomys townsendii) it failed to be sensitive to population reductions due to behavioral differences between the species (Matschke et al., 1994). Bait blocks and tracking tiles were considered for monitoring Cuban hutia (Capromys pilorides) at Guantanomo Bay because they have been applied successfully on a variety of rodents (e.g. Whisson and Engeman, 2003; Whisson et al., 2005; Fiedler, 1994; Chitty, 1954), but the methods first were field tested. These distinct methods both were highly successful for monitoring hutia, and produced highly correlated results (Spearman's rank correlations $>0.89$, Engeman and Witmer, unpublished data).

\subsection{Other useful characteristics}

Other characteristics can make indexing procedures more informative. First, if the observation methods allow simultaneous monitoring of multiple species, then economy of effort is achieved over simultaneously applying different methods for different species. Also, if information on geographic location is collected along with the index observations, then spatial characteristics of the population(s) may also be described. 


\section{General index format}

There has been a tremendous array of indexing procedures applied to many rodent species. Here, an indexing paradigm is provided with a sampling structure in which many existing, or new, observation and measurement methods can be couched for calculating index values with useful statistical properties. The key components to this paradigm are: defining where to make the observations, the time dimension for making observations, the measurements to make, and the data structure and analytical procedures for calculating an index and its variance.

\subsection{Observation stations}

The locations where observations are made will be referred to generically as stations. In practice, each station might be a plot or tile for observing tracks, a chew card, a point where counts are made, a site for measuring bait consumption, a camera location, or even a trap line. Observation stations should be set throughout the survey area of interest, but the distribution of observation stations must be carefully considered relative to efficiency in obtaining adequate measurement of animals, and avoiding biases induced by station placement. Rarely do animals operate in a spatially random pattern. Station locations may take advantage of behavioral characteristics with placement in sites likely to intersect the usual activities of the target animals (Engeman et al., 2002). For example, many rodents preferentially use specific travel ways, such as vole runways, or the much larger tracks used by hutia. Station placement that maximizes encounters with rodents is an efficient means to obtain observations, but they provide a representative sample of the area only if they are distributed throughout the area of interest. Care and common sense must be applied when taking advantage of behavioral characteristics for monitoring animals. If possible, the same station locations should be used for multiple indexing assessments through time (e.g. Ryan and Heywood, 2003). If the area of interest is comprised of different habitat types, then stratifying station placement according to habitat type helps ensure the index reflects the population throughout the area rather than being biased towards (or away from) a particular subset of habitat. Stratification also allows index comparisons among the habitats within the area of interest.

Stations should be dimensionally consistent in preparation. This applies to area dimensions of the stations, as well as to time, weight or any other characteristic of the stations. Thus, not only should stations such as tracking plots, tracking tiles, chew cards have consistent rectangular dimensions, but chew cards should have the same thick- ness, bait-take stations should start with the same amount of bait.

\subsection{Time dimension}

Stations are best observed on more than one occasion during an assessment period to account for variability in animal activity over time. Typically, this means taking measurements at each station on multiple days. For simplicity, the time dimension will be referred to as a day effect. The time elapsed between successive observations at each station should remain constant. For example, if tracking tiles are to be observed $24 \mathrm{~h}$ after preparation, then each succeeding observation should also be made $24 \mathrm{~h}$ after tile preparation.

\subsection{Measurements}

Many types of measurements can fit the above observational structure, including the general categories of animal counts, measurement of animal sign, and catch per unit effort. For the purposes of the methodology presented here, the observations taken at each station preferably should be nonbinary, that is, continuous or unboundedly discrete. The variety of non-binary indexing measurements at different types of observation stations include the number of intrusions by each species onto a dirt tracking plot, the area or proportion of a tracking tile tracked by each species, the proportion or area of a chew card consumed, the number of individuals (e.g. ground squirrels/prairie dogs, muskrats) of each species observed in a fixed amount of time within a fixed distance at each station (standardized by time of day), or the daily number of captures or catch rate from each of a number of trap lines in the area of interest (e.g. Allen et al., 1996; Engeman and Witmer, 2000; Engeman and Whisson, 2003).

Often, potentially continuous measures have been neglected in favor of binary observations, i.e. presence-absence measures at each station. Reduction of potentially continuous data to binary observations is easily demonstrated to be less descriptive and more prone to erroneous inferences (Engeman et al., 1989), which has been welldemonstrated for tracking plot data (e.g. Engeman et al., 2000, 2002). A corollary to the use of continuous rather than binary measures is that stations should be designed so that total saturation at a station is unlikely. That is, an entire chew card would be unlikely to be consumed overnight, not all bait at a bait station would be consumed, or a tracking tile would not be totally obliterated by animal activity. All stations can receive activity, but an increase in intensity can still be detected.

Another valuable measure at each station is its geographical location. Potentially, measuring or calculating distances among stations can be used in conjunction with station observations to index the spatial 
pattern of animal activity within the survey area. One approach modifies Hopkins' (1954) index of aggregation, which has seen other useful modifications (e.g. Engeman and Sugihara, 1998). Defining an active station as one in which the rodent species of interest was detected, then the IP (for index of pervasiveness) is defined mathematically as

$\mathrm{IP}=(1 / n) \Sigma\left(w_{1} / w_{2}\right)$

where $n$ is the number of active stations, $w_{1}$ is the square of the distance from an active tracking station to the nearest active station (nearest neighbor sample, Engeman et al., 1994), and $w_{2}$ is the square of the distance from that nearest station to its nearest active station (second-nearest neighbor sample, Engeman et al., 1994). For entirely random patterns IP $=1$, while IP $>1$ for aggregations of activity (localized concentrations), and IP $<1$ for systematic spatial patterns of activity.

\subsection{Data structure and index calculations}

The data structure, defined by the station placement design and measurement method, provides the framework from which a general index and its variance can be calculated (see Engeman, 2005 for the mathematical framework). The calculation of the general index (GI) begins by taking the mean of the observations across all stations each day (this is done separately for each species if more than one is measured at each station). The GI is the mean of the daily means, and provides an average view of the measurements over space and time within the area of interest. The GI can be written as (Engeman, 2005)

$\mathrm{GI}=\frac{1}{d} \sum_{j=1}^{d} \frac{1}{s j} \sum_{i=1}^{s j} x_{i j}$

and its variance formula is

$\operatorname{var}(\mathrm{GI})=\frac{\sigma_{s}^{2}}{d} \sum_{j=1}^{d} \frac{1}{s j}+\frac{\sigma_{d}^{2}}{d}+\frac{\sigma_{e}^{2}}{d^{2}} \sum_{j=1}^{d} \frac{1}{s j}$

where $x_{i j}$ is the measurement on the $j$ th day $(j=$ day 1,2 , $3 \ldots d)$ from the $i$ th station $\left(i=\right.$ station $1,2,3 \ldots s_{j} \leqslant s$ the number of stations contributing data on the $j$ th day), and the $\sigma_{s}^{2}, \sigma_{d}^{2}$, and $\sigma_{e}^{2}$ are, respectively, the components for station-to-station variability, daily variability, and random observational variability associated with each station each day. A computational procedure such as SAS PROC VARCOMP (SAS Institute, 1996), using restricted maximum likelihood estimation (REML), can be used to calculate the variance components (Searle et al., 1992) needed in the variance estimation formula. The existence of an inherent variance estimate for GI allows application of standard statistical procedures.

In practice, it would be unreasonable to assume that each station would contribute data each day. Tracking plots can be obliterated by livestock or vehicle traffic. Chew cards can become lost. Observations at some stations may be missed due to unforeseen access restrictions. Thus, the number of stations contributing data each day is allowed to vary. Similarly, it would be biologically unreasonable in most circumstances to assume stations are uncorrelated, or that observation days are uncorrelated,. For example, animals may roam greater distances than those separating the stations. Also, stations that are closer together may share more habitat characteristics than do more distantly separated stations. Similarly, environmental or climatic conditions should not be assumed to be unrelated across days of observation. The stations in this sampling framework are not assumed independent of each other nor are days assumed independent of each other, i.e. a nonzero covariance structure is assumed to exist among stations and among days. Hence, the derivation of the variance estimate was not reliant on potentially unrealistic assumptions of independence (Engeman, 2005).

\section{Discussion}

An investigator needs to be clear on the monitoring objectives when deciding whether to estimate the numerical size or density of the population, or whether to apply an index reflective of the population. Given that an indexing procedure would be suitable, a great diversity of rodent observation and measurement methods can be integrated into the general index procedures presented here (Table 1). If a population estimate is mandatory, then it is sensible to initially devote the resources necessary for density estimation. As White (2001) cautioned, "Don't even start the project if you can't do it right." The investigator should be prepared to do all that is necessary in terms of resources and information to adequately design a study to ensure adequate numbers are observed or captured, and data are appropriately modeled without violating the underlying assumptions for the calculations. This is not a simple task. McKelvey and Pearson (2001) found in a five-year literature review of small mammal (primarily rodent) studies that indices were applied twice as frequently as density estimates, but $98 \%$ of the studies resulted in inadequate data for valid mark-recapture population estimation. Such difficulties in meeting the requirements for density estimation procedures led Caughley and Sinclair (1994) to assert that absolute estimates of population size or density require a "leap of faith" concerning the validity of analytical assumptions and the resulting accuracy of estimates. 
Table 1

Examples of the diversity of rodents and observation procedures encompassed by the general indexing paradigm

\begin{tabular}{|c|c|c|c|}
\hline Station example & Potential (nonbinary) measurement & $\begin{array}{l}\text { Examples of potential species } \\
\text { observed }\end{array}$ & $\begin{array}{l}\text { Example citations for the type of } \\
\text { station or measurement }\end{array}$ \\
\hline Dirt tracking plots & $\begin{array}{l}\text { Number of intrusions by each } \\
\text { species into plot }\end{array}$ & $\begin{array}{l}\text { Medium to large rodents, especially } \\
\text { arid habitats }\end{array}$ & Engeman et al. (2002) \\
\hline Tracking tiles/plates & $\begin{array}{l}\text { Proportion/area tile tracked by each } \\
\text { species }\end{array}$ & Rats, hutia, most terrestrial rodents & Engeman (2005), Fiedler (1994) \\
\hline Mound count plot & $\begin{array}{l}\text { Number of mounds or feeder plugs } \\
\text { in plot }\end{array}$ & Pocket gophers & $\begin{array}{l}\text { Anthony and Barnes (1983), } \\
\text { Engeman et al. (1993), Reid et al. } \\
\text { (1966) }\end{array}$ \\
\hline Open hole & Plugged openings to burrows & Pocket gophers & $\begin{array}{l}\text { Engeman et al. (1993, 1999), } \\
\text { Matschke et al. (1994) }\end{array}$ \\
\hline Chew cards & $\begin{array}{l}\text { Proportion/area removed (or } \\
\text { remaining) }\end{array}$ & $\begin{array}{l}\text { Rodents and other small-medium } \\
\text { mammals }\end{array}$ & $\begin{array}{l}\text { Caughley et al. (1998), Engeman and } \\
\text { Witmer (2000) }\end{array}$ \\
\hline Visual observation sites & $\begin{array}{l}\text { Number seen within a fixed time and } \\
\text { distance }\end{array}$ & $\begin{array}{l}\text { Ground squirrels, muskrats, prairie } \\
\text { dogs }\end{array}$ & $\begin{array}{l}\text { Engeman and Whisson (2003), } \\
\text { Fagerstone and Biggins (1986), } \\
\text { Menkens et al. (1990), Powell et al. } \\
\text { (1994), Severson and Plumb (1998) }\end{array}$ \\
\hline Camera station & $\begin{array}{l}\text { Total number seen, or number of } \\
\text { individuals seen (if individuals can } \\
\text { be distinguished in photographs) }\end{array}$ & $\begin{array}{l}\text { Gambian giant pouch rats, black } \\
\text { rats }\end{array}$ & Engeman et al. (accepted) \\
\hline Bait take & $\begin{array}{l}\text { Amount or proportion of bait } \\
\text { removed }\end{array}$ & Rats, voles, hutia, many rodents & $\begin{array}{l}\text { Chitty (1954), Engeman (2005), } \\
\text { Whisson and Engeman (2003), } \\
\text { Whisson et al. (2005) }\end{array}$ \\
\hline Apple slice(s) & $\begin{array}{l}\text { Amount or proportion of apple } \\
\text { removed }\end{array}$ & Voles & Byers (1975), Tobin et al. (1992) \\
\hline
\end{tabular}

Application of the paradigm for data gathering and index calculation helps ensure the resulting index will possess many of the desirable qualities described earlier. Nevertheless, a useful data structure and analytical procedures by themselves do not guarantee an indexing method is suitable for meeting objectives. Considerable room exists for artistry by the investigator in deciding station placement and the measurements methods. Sometimes, a number of methods may be available from which the most appropriate method must be selected. If a proven method is not available, a method successfully applied to a similar species or situation would be a good candidate method to test and apply. Examination of the utility of an indexing procedure is properly approached through experimentation, because fully enumerated wild populations upon which methods can be tested are rare. A straight-forward strategy is to index a population, change that population, and then index the population again. This can be repeated multiple times and is best if a control area with no induced population change is simultaneously monitored using the same indexing method.

An index needs to be monotonic relative to the true population, i.e. it should increase if the population increases and decrease if it decreases. Ideally, the index would have a linear relationship with the population size, but to assume linearity for analytical purposes would transform an index method into a density estimation method, with all of the associated difficulties concerning analytical assumptions. An index's variability determines the statistical detectability for population differences. A method would be selected based on sensitivity to population differences and field logistics. If a seemingly reasonable station placement and observation method do not produce useful results, then minor changes in methods may improve sensitivity to the presence of animals. For example, a chew card might receive little attention by the animal of interest even though populations are high. A change in the impregnating substance could result in an improved response. But clearly, a chew card index calculated from responses using one impregnating substance is an entirely different index, and not comparable to, an index calculated from responses using a different impregnating substance.

Some observational methods that can fit into the GI format are suitable for simultaneously monitoring multiple species of animals (e.g. tracking stations, camera stations, visual counts). This allows inferences on relative population levels within each of multiple species, but comparison 
of index values across species is not appropriate. For example, consider monitoring multiple species using intrusions to camera stations. Different species would have different home ranges and travel rates, therefore different probabilities of encountering a camera. Hence, GI values would differ among species even if their populations were the same.

The variance components calculated for use in the GI variance formula can provide helpful planning information (e.g. Searle et al., 1992). The relative contributions of station-to-station variation and day-to-day variation can be examined to optimize the combination of days and stations for subsequent indexing assessments, although logistics and resources often are the most important influences on sampling designs.

\section{Acknowledgments}

K. Fagerstone, B. Kimball, T. Mathies, R. Sterner, K. VerCauteren provided helpful reviews of the manuscript.

\section{References}

Allen, L., Engeman, R.M., Krupa, H., 1996. Evaluation of three relative abundance indices for assessing dingo populations. Wildlife Research 23, 197-206.

Anthony, R.M., Barnes Jr., V.G., 1983. Plot occupancy for indicating pocket gopher abundance and conifer damage. In: Kaukeinen, D.E. (Ed.), Vertebrate Pest Control and Management Materials: Fourth Symposium, ASTM STP 817. American Society for Testing and Materials, Philadelphia, PA, pp. 247-255.

Burnham, K.P., Anderson, D.R., Laake, J.L., 1980. Estimation of density from line transect sampling of biological populations. Wildlife Monographs 72, 1-202.

Byers, R.E., 1975. A rapid method for assessing pine vole control in orchards. Horticulture Science 10, 391-392.

Caughley, G., 1977. Analysis of Vertebrate Populations. Wiley, New York, NY.

Caughley, G., Sinclair, A., 1994. Wildlife Ecology and Management. Blackwell Science, Cambridge, MA.

Caughley, J., Donkin, C., Strong, K., 1998. Managing mouse plagues in rural. Vertebrate Pest Conference 18, 160-165.

Chitty, D., 1954. Control of Rats and Mice. Clarendon Press, Oxford, UK.

Engeman, R.M., 2003. More on the need to get the basics right: population indices. Wildlife Society Bulletin 31, 286-287.

Engeman, R.M., 2005. O1_MRKO1_MRKA methodological and analytical paradigm for indexing animal populations applicable to many species and observation methods. Wildlife Research 32, 203-210.

Engeman, R.M., Sugihara, R.T., 1998. Optimization of variable area transect sampling using Monte Carlo simulation. Ecology 79, $1425-1434$.

Engeman, R.M., Whisson, D.A., 2003. A visual method for indexing muskrat populations. International Biodeterioration and Biodegradation 52, 101-106.

Engeman, R.M., Witmer, G.W., 2000. IPM strategies: indexing difficult to monitor populations of pest species. Vertebrate Pest Conference 19, $183-189$.

Engeman, R.M., Sugihara, R., Pank, L., Dusenberry, W., 1994. A comparison of plotless density estimators using Monte Carlo simulation. Ecology 75, 1769-1779.
Engeman, R.M., Campbell, D.L., Evans, J., 1993. A comparison of 2 activity measures for northern pocket gophers. Wildlife Society Bulletin 21, 70-73.

Engeman, R.M., Otis, D.L., Bromaghin, J.F., Dusenberry, W.E., 1989. On the use of the $\mathrm{R}_{50}$. In: Fagerstone, K., Curnow, R. (Eds.), Vertebrate Pest Control and Management Materials. vol. 6, STP1055. American Society for Testing and Materials, Philadelphia, PA, pp. $13-18$

Engeman, R.M., Nolte, D.L., Bulkin, S.P., 1999. Optimization of the open-hole method for assessing pocket gopher activity. Canadian Field Naturalist 113, 241-244.

Engeman, R.M., Pipas, M.J., Gruver, K.S., Allen, L., 2000. Monitoring coyote populations with a passive activity index. Wildlife Research 27, 553-557.

Engeman, R.M., Pipas, M.J., Gruver, K.S., Bourassa, J., Allen, L., 2002. Plot placement when using a passive tracking index to simultaneously monitor multiple species of animals. Wildlife Research $29,85-90$.

Engeman, R.M., Woolard, J.W., Perry, N.D., Witmer, G., Hardin, S., Brashears, L., Smith, H., Muiznieks, B., Constantin, B., accepted. Rapid assessment for a new invasive species threat: the case of the Gambian giant pouched rat in Florida. Wildlife Research.

Fagerstone, K.A., Biggins, D.E., 1986. Comparison of capturerecapture and visual count indices of prairie dog densities in black-footed ferret habitat. Great Basin Naturalist Memoirs 8, 94-98.

Fiedler, L.A., 1994. Rodent Pest Management in Eastern Africa. Food and Agriculture Organization of the United Nations, Rome, Italy.

Hopkins, B., 1954. A new method for determining the type of distribution of plant individuals. Annals of Botany, New Series 18, 213-227.

Krebs, C.J., 1998. Ecological Methodology. Benjamin/Cummings, Menlo Park, CA.

Leidloff, A.C., 2000. Habitat utilisation by the Grassland Melomys (Melomys burtoni) and the swamp rat (Rattus lutrelus) in a coastal heathland of Bribie Island, South-East Queensland. Ph.D. Dissertation, Queensland University of Technology, Brisbane, Queensland, Australia.

Matschke, G.H., Sterner, R.T., Engeman, R.M., O’Brien, J.M., 1994. Limitations of open-hole and plot occupancy indices in field efficacy studies with Townsend's pocket gophers. Proceedings of the 15th Annual SETAC Meeting, vol. 15, Denver, CO, p. 245.

McKelvey, K.S., Pearson, D.E., 2001. Population estimation with sparse data: the role of estimators versus indices revisited. Canadian Journal of Zoology 79, 1754-1765.

Menkens, G.E.JR., Biggins, D.E., Anderson, S.H., 1990. Visual counts as an index of white-tailed prairie dog density. Wildlife Society Bulletin 18, 290-296.

Otis, D.L., Burnham, K.P., White, G.C., Anderson, D.R., 1978. Statistical inference from capture data on closed animal populations. Wildlife Monographs 62.

Powell, K.L., Robel, R.J., Kemp, K.E., Nellis, M.D., 1994. Above ground counts of black-tailed prairie dogs: temporal nature and relationship to burrow entrance density. Journal of Wildlife Management 58, 361-366.

Proulx, G., Gilbert, F.F., 1984. Estimating muskrat population trends by house counts. Journal of Wildlife Management 48, 917-922.

Reid, V.H., Hansen, R.M., Ward, R.L., 1966. Counting mounds and earth plugs to census mountain pocket gophers. Journal of Wildlife Management 30, 327-334.

Ryan, D.A., Heywood, A., 2003. Improving the precision of longitudinal ecological surveys using precisely defined observational units. Environmetrics 14, 283-293.

SAS Institute, 1996. SAS/STAT User's Guide. SAS Institute, Carey, NC.

Searle, S.R., Casella, G., McCulloch, C.E., 1992. Variance Components. Wiley, New York, NY. 
Severson, K.E., Plumb, G.E., 1998. Comparisons of methods to estimate population densities of black-tailed prairie dogs. Wildlife Society Bulletin 26, 859-866.

Tobin, M.E., Richmond, M.E., Engeman, R.M., 1992. Comparison of methods for detecting voles under apple trees. Proceedings of the Eastern Wildlife Damage Control Conference 5, 201-204.

Whisson, D.A., Engeman, R.M., 2003. Indexing techniques for measuring relative abundance of California meadow voles Microtus spp. Final
Report to California Department of Food and Agriculture - Contract 01-0516.

Whisson, D.A., Engeman, R.M., Collins, K., 2005. Developing relative abundance techniques (RATS) for monitoring rodent populations. Wildlife Research 32, 239-244.

White, G.C., 2001. Why take calculus? Rigor in wildlife management. Wildlife Society Bulletin 29, 380-386. 